\title{
NEUROPHYSIOLOGICAL CORRELATES OF EXCITEMENT IN MEN WITH RECENT-ONSET PSYCHOSIS
}

\author{
Alexander Sumich ${ }^{1,2}$, Anthony Harris ${ }^{3}$, Thomas Whitford ${ }^{4,5}$, Daniel Hermens ${ }^{6}$, Nadja Heym ${ }^{1}$, \\ John Anderson ${ }^{1}$, Claire Bloxsom ${ }^{1}$, Fraenze Kibowski ${ }^{1}$ \& Veena Kumari ${ }^{2,7}$ \\ ${ }^{1}$ Division of Psychology, Nottingham Trent University, Nottingham, UK \\ ${ }^{2}$ Department of Psychology, King's College London, Institute of Psychiatry, Psychology and Neuroscience, UK \\ ${ }^{3}$ Discipline of Psychiatry, Sydney Medical School, University of Sydney, Sydney, Australia \\ ${ }^{4}$ The Brain Dynamics Centre, Westmead Millennium Institute, Westmead Hospital, and Westmead Clinical School, \\ Sydney Medical School, Westmead Hospital, Sydney, Australia \\ ${ }^{5}$ School of Psychology, UNSW Australia, Sydney, NSW, 2052, Australia \\ ${ }^{6}$ Clinical Research Unit, Brain and Mind Research Institute, University of Sydney, Camperdown 2050, NSW, Australia \\ ${ }^{7}$ Centre for Cognitive Neuroscience, College for Life Science, Brunel University London, London, UK
}

received: 8.5.2017;

revised: 2.8.2017;

accepted: 7.12.2017

\section{SUMMARY}

Objective: Right frontal function, as indicated by the N200 component of the event-related potential during target detection, has previously been associated with excitement (excitement, impulsivity, hostility, uncooperativeness) in men with a long-term diagnosis of schizophrenia. The current study investigated excitement in relation to N200 in men who had recently experienced their first episode of psychosis.

Subjects and methods: Twenty men who had recently suffered their first psychotic episode underwent a clinical interview and auditory oddball task.

Results: Multiple linear regression analysis showed that 58\% of the variance in the excitement symptom cluster was explained by a positive association with frontal midline N200 amplitude and an inverse association with right frontal N200 amplitude. The latter was not apparent in the initial correlation, suggesting suppression by the midline activity. These associations were not explained by drug use, medication or negative symptoms. However, the correlation between excitement and midline N200 was stronger in drug users, and that between right frontal N200 and excitement was stronger in nonusers.

Conclusion: Findings support the independent contributions to excitement of mechanisms reflected in midline and right frontal N200 amplitude respectively during the early stages of psychosis.

Key words: psychosis - recent-onset - event-related potentials - N200 - excitement - drug use

Abbreviations: ERP - Event-related potential; BRC - Brain Resource Company; DSM-IV - Diagnostic and Statistical Manual of Mental Disorders; PANSS - Positive and Negative Symptoms Scale; EOGh - Horizontal electroocculogram; EOGv - Vertical electroocculogram; ADHD - attention deficit hyperactivity disorder; MMN - mismatch negativity; NMDA - N-methyl-D-aspartate

\section{INTRODUCTION}

Excitement describes a cluster of symptoms (excitement, impulsivity, hostility, uncooperativeness) (Lindenmayer et al. 2004, van der Gaag et al. 2006) that are more prominent in acute and transient psychosis than schizophrenia (Esan \& Fawole 2013), and have been associated with several clinical complications and adverse behavioural outcomes (e.g. treatment non-adherence, compulsory admission, increased risk of violent behaviour, substance use) (Colasanti et al. 2010, Montemagni et al. 2010, Schiffer et al. 2010, Kaladjian et al. 2011, Yang et al. 2012). Brain networks involved in target detection, conflict monitoring and cognitive control have been implicated in traits and symptoms associated with excitement (Czobor \& Volavka 1993, Hoptman et al. 2002, Kaladjian et al. 2007, Barkataki et al. 2008, Kumari et al. 2009, Schiffer et al. 2010, Kaladjian et al. 2011, Nishimura et al. 2011). In particular, atypical activation of medial, dorsolateral, fronto-polar and ventral frontal regions has been observed, and may be in part moderated by sex (Sumich et al. 2013). Whether similar mechanisms underpin excitement early in the illness course remains unclear.

Event-related potential (ERP) components index temporally contiguous information processing stages (Luck 2005). A negative deflection in the auditory ERP occurs at approximately 200ms post-stimulus in response to identification and categorisation of target stimuli. This N200 response comprises several subcomponents that vary slightly in scalp distribution and reflect several fronto-temporal and fronto-parietal mechanisms with functional significance to excitement, including autonomic alerting, discrimination, behavioural/conflict monitoring, template matching and cognitive control (van Veen \& Carter 2002, Patel \& Azzam 2005, Crottaz-Herbette \& Menon 2006, Kopp et al. 2006). N200 amplitude is generally reduced in schizophrenia (O'Donnell et al., 2004, Doege et al., 2010). Sumich et al. (2013) report an inverse association between the 
severity of excitement and right frontal N200 amplitude in response to auditory targets in men with an established diagnosis of a schizophrenia spectrum disorder (mean illness duration=20 years). Another study in men with recent onset psychosis found that right N200 amplitude was positively associated with negative symptoms, which are arguably conceptual opposite to excitement (Sumich et al. 2006). Indeed, such findings are in line with activation of right frontal mechanisms during states of withdrawal, usually measured as a reduction in right alpha power (Jesulola et al. 2015).

The current study is secondary analyses of data presented in Sumich et al. (2006) and seeks to replicate the association between right anterior N200 and excitement in a group of men with recent onset psychosis. It is predicted that right frontal N200 amplitude, relative to left and midline, would be inversely associated with excitement. Furthermore, whether negative symptoms moderate this relationship or have an independent contribution to right N200 amplitude is unclear, and was therefore also investigated.

\section{SUBJECTS AND METHODS}

The standardised Brain Resource International Database methodology (under the auspices of the Brain Resource Company, BRC) was used to assess patients and controls. The BRC standardised protocol has high interlab reliability (for details see www.brainresource.com and www.brainnet.org.au (Williams et al. 2005). Assessment procedures were approved by t Local Health District Human Research Ethics Committee. he Western Sydney

\section{Participants}

Twenty right-handed men (age: mean=20.0 years, $\mathrm{sd}=3.2$; education mean=11.4 years, $\mathrm{sd}=2.2$ ) who had recently experienced their first psychotic episode were recruited from The Early Psychosis Intervention Program at Liverpool and Westmead Hospitals, Sydney, Australia. Mean age of onset of first psychotic symptoms was 18.45 years (range 14-24 years, sd=2.89). Mean duration of illness was 1.67 years (range 0.155.22, sd=1.03). Fourteen patients were currently receiving treatment (Chlorpromazine equivalence over 4 weeks prior to assessments mean $=387.46$, range 200833, sd=194.84).

Data on the association of G12, negative symptoms and right N200 amplitude in this sample has been previously published (Sumich et al. 2006). Descriptive statistics for demographic and clinical information are presented in table 1. Diagnosis of schizophrenia or schizophreniform disorder was confirmed by structured clinical interview for the Diagnostic and Statistical Manual of Mental Disorders (DSM-IV) (Spitzer et al. 1990) administered by qualified research psychiatrists. Patients were also assessed on the (Positive and Negative Symptoms Scale, PANSS; interrater-reliability $r=0.80$ ) (Kay et al. 1987). Nine participants admitted to recreational drug use (alcohol, cannabis, hallucinogenics, stimulants, narcotics, sedatives, inhalants) within the month preceding assessment. Nine stated they had not used recreational drugs within the last month, and 2 chose not to disclose information.

\section{Excitement}

Based on findings from a 10 fold cross validation study ( $\mathrm{n}=5769$ ) (van der Gaag et al. 2006), the excitement cluster was calculated as the sum of the ratings on two general and two positive items on the PANSS: excitement (P4), hostility (P7) and poor impulse control (G14) and uncooperativeness (G8). The first three items have been found to load consistently and specifically on the excitement cluster (Lindenmayer et al. 2004). Whilst several studies show moderate loadings $(0.35)$ of uncooperativeness onto negative symptoms (van der Gaag et al. 2006), stronger loadings (0.6) are seen with the excitement cluster, and it was therefore included in calculation of excitement and excluded from calculation of negative symptoms. Grandiosity (P5), poor rapport (N3) and active social withdrawal (G16) load less consistently on the excitement cluster, and have stronger associations with negative symptoms, so were not included in the calculation. Likewise tension (G4) has less consistent association with excitement than emotional distress.

\section{Negative Symptoms}

Negative symptoms were calculated as the sum of Lack of spontaneity and conversational flow (N6) + Blunted affect (N1) + Emotional withdrawal (N2) + Passive/apathetic social withdrawal (N4) + Motor retardation (G7) + Poor rapport (N3) + Active social avoidance (G16). In contrast to Sumich et al. (2006), G8 was excluded from calculation of negative symptoms in the current study; as mentioned, due to stronger loading with excitement. Also, given that only few studies have found inverse loadings (-0.42) for Conceptual disorganisation (P2) on negative symptoms, this item was not included in the calculation.

\section{ERP assessment}

ERP assessment was performed on the same day as the clinical assessment in 12 patients, within one week of clinical assessment in 6 patients, and within two weeks of clinical assessment in 2 patients. The auditory oddball task was administered following 4 minutes of resting electroencephalographic data collection.

\section{Task}

Participants were presented binaurally with 80 target tones $(1000 \mathrm{~Hz})$ dispersed quasi-randomly (two targets never appeared together) amongst a series of 320 background tones $(500 \mathrm{~Hz})$ (intensity $=75 \mathrm{~dB}$; duration= 50ms; ISI=1s; r/f =5ms). Participants were instructed to 
press two buttons simultaneously with the index finger of each hand, as fast and as accurately as possible in response to target tones, and not to respond to background tones. The duration of the task was approximately seven minutes.

\section{Recording and signal processing}

ERP assessments used Brain Resource Company methodology (www.brainresource.com) (Williams et al. 2005). Participants sat in a sound and light attenuated room, with an ambient temperature of $24^{\circ} \mathrm{C}$. A NeuroScan Quik-cap (NuAmps amplifier; sampling rate $=500 \mathrm{~Hz}$ ) was used to collect electroencephalographic data from 23 electrode sites $(\mathrm{Ag} / \mathrm{AgCl})$, which were located on the basis of the 10-20 system. Continuous data were recorded relative to linked mastoids with a forehead ground.

\section{Signal processing}

A low pass filter $(100 \mathrm{~Hz}, 40 \mathrm{~dB})$ was used prior to digitisation. Horizontal eye movement (EOGh) was recorded with electrodes placed $1.5 \mathrm{~cm}$ lateral to the outer canthus of each eye. Vertical eye movement (EOGv) was recorded from the left eye with electrodes placed $3 \mathrm{~mm}$ above the middle of the eyebrow and $1.5 \mathrm{~cm}$ below the lower eye-lid. Electrode impedance was maintained below 5 kOhms. Both EOGh and EOGv were used in offline correction of EOG artefact (Gratton et al. 1983). Offline, data were filtered with a $25 \mathrm{~Hz}$ lowpass filter, and baselined ( $-300-0 \mathrm{msec}$ prestimulus) to an average amplitude of zero. Only data from correct responses were included in the averaged ERP. All averages contained at least 30 trials.

\section{ERP assessment}

All participants refrained from smoking before task performance ( $>1$ hour). They sat alert and still with eyes open and fixed on a focal point.

N200 was scored as the most negative peak between 150-350ms post-stimulus at Fz, F3, F4, F7, F8 in response to target stimuli. Due to small sample size, with the view to minimising within groups variables, data reduction was performed by calculating the mean at midline $(\mathrm{Fz})$, left $((\mathrm{F} 3+\mathrm{F} 7) / 2)$ and right $((\mathrm{F} 4+\mathrm{F} 8) / 2)$ sites. Additive inverse values for N200 (i.e. value*-1) were used in correlation and regression analysis. Behavioural measures are presented elsewhere (Sumich et al. 2006), and included the number of hits in response to targets, mean reaction time to hits and standard deviation of reaction time to hits.

\section{Statistics}

Pearson tests were used to analyse the correlations between excitement and N200 at midline, left and right sites. Due to multiple comparisons, alpha criteria for significance were set at $\mathrm{p}<0.016$ ). Hierarchical multiple linear regression was used to predict excitement with midline N200 amplitude entered as an initial predictor (model 1), followed by amplitude left and right sites (model 2).

\section{RESULTS}

Table 1 shows the descriptive statistics for the sample and the clinical and ERP measures. Only midline N200 showed a significant positive correlation with excitement $(\mathrm{r}=0.62, \mathrm{p}=0.002)$. Table 2 shows the results of linear regression. Figure 1 shows scatters plots of the partial correlations between N200 at each electrode sites (left, right, midline) and standardised scores for excitement. Midline N200 explained 38\% of the variance in excitement (model 1: adjusted $\mathrm{R}^{2}=0.35 ; \mathrm{F}(1,18)=11.09$, $\mathrm{p}=0.004$; sum of squares regression $=42.62$, residual =69.18). The addition of left and right N200 explained a further $20 \%$ of the variance (model 2: adjusted $\mathrm{R}^{2}=0.50$; $\mathrm{F}(3,16)=7.36, \mathrm{p}=0.003$; sum of squares regression $=64.82$, residual $=46.98$, change in $R^{2} p=0.045$ ). Midline frontal N200 amplitude showed a significant positive relationship, and right frontal N200 amplitude showed a significant inverse association, with excitement. Left frontal N200 did not significantly contribute to the model. These associations remained after controlling for a binary variable of recreational drug use (nonusers $=0$, users=1) and medication (chlorpromazine equivalence) within the last month.
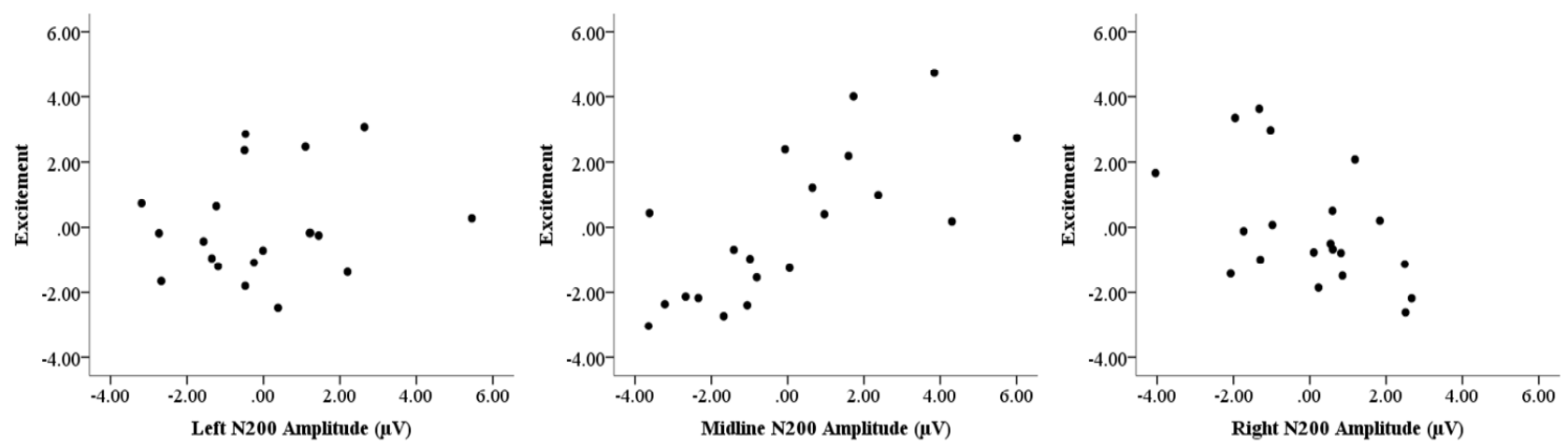

Figure 1. Scatter plots of the partial correlations between excitement (standardised) and frontal N200 amplitude at each scalp region (left, right, midline) 
Table 1. Means and standard deviations (sd) demographic, clinical and N200 (V) measures

\begin{tabular}{lccrc}
\hline & Minimum & Maximum & Mean & sd \\
\hline Age (years) & 14.90 & 25.59 & 20.06 & 3.23 \\
Education (years) & 9.00 & 17.00 & 11.40 & 2.21 \\
Age of onset (years) & 14 & 24 & 18.45 & 2.89 \\
Illness duration (years) & 0.15 & 5.22 & 1.61 & 1.04 \\
Total PANSS & 35 & 112 & 72.65 & 18.13 \\
Excitement & 4.00 & 12.00 & 6.90 & 2.43 \\
Negative symptoms & 8 & 32 & 19.85 & 8.16 \\
Midline N200 $(\mu \mathrm{V})$ & 1.92 & 15.15 & 5.79 & 4.75 \\
Right N200 $(\mu \mathrm{V})$ & 2.79 & 13.93 & 5.42 & 4.36 \\
Left N200 $(\mu \mathrm{V})$ & 1.33 & 15.61 & 5.98 & 4.16 \\
\hline
\end{tabular}

PANSS=Positive and Negative Syndrome Scale; Additive inverse used for N200 amplitude

Table 2. Linear regression models of excitement as predicted by anterior N200 amplitude

\begin{tabular}{llrrrrrrr}
\hline & & $B^{*}$ & SE & Beta** & t & P & Tolerance & VIF \\
\hline Model 1 & (Constant) & 4.762 & 0.778 & & 6.124 & $<0.001$ & & \\
& Midline & 0.315 & 0.095 & 0.617 & 3.330 & 0.004 & 1.000 & 1.000 \\
Model 2 & (Constant) & 4.686 & 0.735 & & 6.375 & $<0.001$ & & \\
& Midline & 0.629 & 0.145 & 1.232 & 4.323 & 0.001 & 0.324 & 3.090 \\
& Right & -0.534 & 0.222 & -0.960 & -2.412 & 0.028 & 0.166 & 6.031 \\
& Left & 0.141 & 0.191 & 0.242 & 0.740 & 0.470 & 0.245 & 4.081 \\
\hline
\end{tabular}

*Unstandardised; **standardised; Italics= significant coefficient

Table 3. Relative contribution to right anterior N200 amplitude by excitement and negative symptoms, controlling for midline frontal N200 amplitude

\begin{tabular}{llrrrrrrr}
\hline & & $\mathrm{B} *$ & $\mathrm{SE}$ & \multicolumn{1}{c}{ Beta** } & $\mathrm{t}$ & $\mathrm{P}$ & Tolerance & VIF \\
\hline Model 1 & (Constant) & 0.304 & 1.010 & & 0.301 & 0.767 & \\
& Midline & 0.754 & 0.123 & 0.822 & 6.131 & $<0.001$ & 1.000 & 1.000 \\
Model 2 & (Constant) & 3.679 & 1.530 & & 2.405 & 0.028 & \\
& Midline & 0.977 & 0.135 & 1.066 & 7.249 & $<0.001$ & 0.619 & 1.616 \\
& Excitement & -0.709 & 0.264 & -0.395 & -2.684 & 0.016 & 0.619 & 1.616 \\
Model 3 & (Constant) & 0.834 & 1.708 & & 0.488 & 0.632 & & \\
& Midline & 0.906 & 0.119 & 0.988 & 7.592 & $<0.001$ & 0.587 & 1.704 \\
& Excitement & -0.639 & 0.229 & -0.356 & -2.788 & 0.013 & 0.610 & 1.638 \\
& Negative & 0.143 & 0.055 & 0.269 & 2.620 & 0.019 & 0.947 & 1.056 \\
\hline
\end{tabular}

*Unstandardised; **standardised; Italics= significant coefficient

In order to further check the role of drug use, correlations between midline N200 and excitement were tested separately in nonusers and users. This showed significant positive associations in users $(\mathrm{r}=0.86$, $\mathrm{p}=0.003, \mathrm{n}=9$ ), that did not reach significance in nonusers $(r=0.52, p=0.15)$. Partial correlations between excitement and right N200 amplitude (controlling for midline N200 amplitude) were significant in nonusers $(\mathrm{r}=-0.83, \mathrm{p}=0.01)$, but not in users $(\mathrm{r}=-0.24, \mathrm{p}=0.57)$. Multivariate analysis of variance showed a trend for higher amplitudes in drug users than nonusers $(\mathrm{F}(3,14)=2.69, \mathrm{p}=0.087$, partial eta squared $=0.37)$. Univariate analysis suggested higher amplitudes in users than nonusers in the left hemisphere $(F(1,16)=5.54$, $\mathrm{p}=0.032$, partial eta squared $=0.26$; users: mean $=7.9 \mu \mathrm{V}$, sd=4.46 $\mu \mathrm{V}$; nonusers: mean $=3.65 \mu \mathrm{V}$, sd=3.15). A similar, but nonsignificant, pattern was seen at midline $(F(1,16)=0.87, p=0.36$, partial eta squared $=0.05$; users: mean $=8.05 \mu \mathrm{V}$, sd=3.76 $\mu \mathrm{V}$; nonusers: mean $=5.84 \mu \mathrm{V}$, $\mathrm{sd}=6.02)$ and right $(\mathrm{F}(1,16)=1.37, \mathrm{p}=0.26$, partial eta squared=0.08; users: mean $=6.41 \mu \mathrm{V}$, sd=3.96 $\mu \mathrm{V}$; nonusers: mean $=3.93 \mu \mathrm{V}$, sd=4.95) sites (Table 3).

A second hierarchical linear regression was conducted to test the relative contribution of excitement and negative symptoms on right frontal N200; after controlling for midline N200 (level 1). As expected, midline frontal N200 explained the majority (67.6\%) of the variance in right frontal N200 (model 1: adjusted $\mathrm{R}^{2}=0.66 ; \quad \mathrm{F}(1,18)=37.58, \mathrm{p}<0.001 ;$ sum of squares regression=243.82, residual=116.77). However, a further $10 \%$ of the variance was explained by excitement symptoms (model 2: adjusted $\mathrm{R}^{2}=0.75 ; \mathrm{F}(2,17)=28.87$, $\mathrm{p}<0.001$; sum of squares regression $=278.57$, residual $=82.02$, change in $\mathrm{R}^{2} \mathrm{p}=0.016$ ). Finally, negative symptoms added significantly in explaining a further $7 \%$ of the variance in right N200 amplitude (model 3: 
adjusted $\mathrm{R}^{2}=0.81 ; \mathrm{F}(3,16)=28.18, \mathrm{p}<0.001 ;$ sum of squares regression $=303.33$, residual $=57.26$, change in $\mathrm{R}^{2} \mathrm{p}=0.019$ ). Excitement and negative symptoms showed independent and opposing associations with right frontal N200 amplitude.

\section{DISCUSSION}

The current study replicates, in men with recentonset psychosis, a previously observed inverse association between right frontal N200 amplitude and excitement in schizophrenia with longer illness duration (Sumich et al. 2013). Moreover, it demonstrates suppression of this relationship by the positive association between midline N200 and severity of excitement. These effects were not explained by the inverse association between negative symptoms and right frontal N200 amplitude (previously reported in this group) (Sumich et al. 2006). Nor was it explained by prescribed medication (chlorpromazine equivalence) or recreational drug use. Thus, excitement may, in part, be due to the relationship between mechanisms underpinning midline and lateral frontal N200.

Studies using other modalities have also implicated frontal regions in excitement and related behaviours. For example, in a near infrared spectroscopy study, excitement was positively associated with hyperactivity of the right dorsolateral and frontopolar regions during a response inhibition task, but inversely related to adjacent (caudal and ventral) recording sites (Nishimura et al. 2011).

Given that attention deficit hyperactivity disorder (ADHD) shares some behavioural traits with excitement, findings from ADHD studies may be useful in interpreting current results. For example, neuroimaging data implicates connectivity between dorsal ACC and right ventrolateral prefrontal activity in response inhibition and in ADHD (Elton et al. 2013). Also, given that the anterior cingulate cortex has been proposed as a source of the midline frontal N200 (Van Veen \& Carter 2002), the finding that adults with ADHD show ACC hyperactivation during a working memory task with low cognitive load (Ko et al. 2013) mirrors the current results for midline N200 amplitude. Ko and colleagues interpreted ACC hyperactivation as reflecting greater effort spent in completing a relatively easy task. High N200 amplitude has also been observed with increased discrimination difficulty (see review, Huster et al. 2013) and in young children, where it decreases with age (Sumich et al. 2012). Hyperactivity of the midline N200 in relation to excitement could therefore reflect atypical development. Reduction in N200 amplitude with development has been interpreted as reflecting cortical restructuring, and parallels the decline in cortical thickness and the development of early components (e.g., N100) with maturation (Sumich et al. 2012).

Midline N200 is believed to be generated in part by theta range coupling of conflict detection and prediction neurons in the midcingulate gyrus (Cavanagh \& Shackman 2015). Activity from these neurons is linked to trait anxiety and facilitates response inhibition during uncertainty, conflict and/or cognitive interference; when there is a need for greater cognitive control (Nigbur et al. 2011, Lin et al. 2014, Cavanagh \& Shackman 2015). High N200 amplitude in relation to excitement might, therefore, reflect the need for greater resources in the context of conflict from endogenous cognitive interference (e.g. racing thoughts) and/or response uncertainty.

It is also possible that findings reflect a midline component that temporally overlaps the N200, the mismatch negativity (MMN) (Todd et al. 2008). MMN is associated with $\mathrm{N}$-methyl-D-aspartate (NMDA) receptor function and has higher amplitude in men with antisocial personality disorder, which demonstrates traits similar to those of the excitement cluster in psychosis: impulsivity, hostility, uncooperativeness (Liu et al. 2007). A relationship between frontal midline N200 amplitude and excitement was not observed in men with a longer duration of illness (Sumich et al. 2006), which suggests potential changes to underlying mechanisms with illness progression. Indeed, reduced medial frontal glutamate function has been observed in chronic schizophrenia, but not first-episode psychosis (Natsubori et al. 2014), Thus, it is possible that the association between midline N200 and excitement in the current study, in part reflects intact glutamatergic cingulate signalling and frequency $\mathrm{MMN}$ in relation to excitement in the early stages of psychosis, which becomes deregulated with longer duration of illness (Todd et al. 2008). Further studies utilising tasks designed specifically to test MMN will confirm this. In partial support to this however, frontal MMN has been shown to inversely correlate with negative symptoms (Oades et al. 2006).

With regard to right lateral N200 amplitude, there is some evidence for a ventral prefrontal source for N200 (Neshige \& Lüders 1992). Thus, current findings are in line with deactivations observed by Nishimura et al. (2011), using near infrared spectroscopy, in relation to excitement. In contrast however, Kaladjian et al. (2007) found a positive association between impulsivity in schizophrenia and the blood oxygen level dependence response in the right ventral prefrontal cortex which was interpreted as inefficient activation of this region. Inconsistencies might reflect differences between studies in test population and cognitive tasks used (go, no go, stop). A comparison across tasks and other neuroimaging modalities will lead to a better understanding of the functional significance of the association between N200 and excitement, and of the underpinning neural mechanisms.

Evidence implicates D1/D2 signalling in the frontal N200, although the relationship does not appear simple. Nevertheless, dopamine (D1/D2) agonists have been shown to increase frontal N200 amplitude (RangelGomez et al. 2013), and depletion of dopamine with 
branched chain amino acids reduces N200 amplitude (Neuhaus et al. 2009). Thus, disease-related changes to dopamine systems could underpin the relationship between N200 and excitement. Dopamine systems would also be expected to be affected by medication and a history of recreational drug use. Whilst controlling for medication dose (chlorpromazine equivalence) did not appear to affect findings, current data cannot rule out a role for recreational drugs. In ADHD, the presence of life-time illicit drug use was associated with increased right ventro-frontal activation during a stop task (Whelan et al. 2012). In comparison, drug users in the current study had higher left N200 amplitude, which could reflect drug induced sensitisation of dopamine systems. However, given that the multivariate analysis only reached trend level, these findings should be viewed with caution. Whilst drug use did not fully explain the association between midline (or right lateral N200) amplitude and excitement, this relationship was stronger in the subgroup of drug users. In comparison, the inverse association between right lateral N200 and excitement (after controlling for midline N200) was stronger for nonusers, than users. Thus, it remains possible that the presence of drug use in a large proportion of our sample affected findings, and this should be further investigated in larger cohorts of users and non-users.

\section{CONCLUSION}

Whilst sample size is low, warranting caution, findings add to a growing body of literature implicating medial and right lateral frontal mechanisms in excitement, which are not fully explained by antipsychotic use or negative symptoms. Recreational drug use, however, might in part have affected findings for the left hemisphere and midline N200. The current study focused on the N200 response to target stimuli, however right frontal P300 amplitude in response to novel stimuli has previously been found to be inversely associated with excitement in women with schizophrenia. Further studies are therefore needed to understand brain networks associated with excitement in women with recent-onset psychosis. Direct comparisons across various stages of illness will further improve understanding of how the disease process affects these relationships. A corollary here is that excitement might respond differentially to treatment in early and late stage psychosis.

\section{Acknowledgements:}

We thank the individuals who gave their time to participate in the study.

\section{Financial support}

The authors acknowledge and thank the BIAL foundation (90/02 to AS) for funding of the study. BIAL foundation and the Brain foundation had no other role in the conduct of write-up of this study.

\section{Conflict of interest: None to declare.}

\section{Contribution of individual authors:}

Alexander Sumich: statistical analysis and author of first draft;

Anthony Harris, Thomas Whitford \& Daniel Hermens: clinical expertise, participant recruitment, clinical assessment and EEG data collection and processing, intellectual contribution to second draft and editing;

Nadja Heym, John Anderson, Claire Bloxsom \& Veena Kumari: Intellectual contribution to second draft and editing.

\section{References}

1. Barkataki I, Kumari V, Das $M$, Sumich A, Taylor $P$, Sharma T: Neural correlates of deficient response inhibition in mentally disordered violent individuals. Behav Sci Law 2008; 26:51-64

2. Cavanagh JF, Shackman AJ: Frontal midline theta reflects anxiety and cognitive control: Meta-analytic evidence. J Physiol Paris 2015; 109:3-15

3. Colasanti A, Paletta S, Moliterno D, Mazzocchi A, Mauri MC, Altamura AC: Symptom dimensions as predictors of clinical outcome, duration of hospitalization, and aggressive behaviours in acutely hospitalized patients with psychotic exacerbation. Clin Pract Epidemiol Ment Health 2010; 6:72-78

4. Crottaz-Herbette S, Menon V: Where and when the anterior cingulate cortex modulates attentional response: combined fMRI and ERP evidence. J Cogn Neurosci 2006; 18:766-780

5. Czobor P, Volavka J: Quantitative electroencephalogram examination of effects of risperidone in schizophrenic patients. J Clin Psychopharmacol 1993; 13:332-42

6. Doege K, Kumar M, Bates AT, Das D, Boks MP, Liddle PF: Time and frequency domain event-related electrical activity associated with response control in schizophrenia. Clin Neurophysiol 2010; 121:1760-1771

7. Elton A, Tripathi SP, Mletzko T, Young J, Cisler JM, James GA, Kilts CD: Childhood maltreatment is associated with a sex-dependent functional reorganization of a brain inhibitory control network. Hum Brain Mapp 2013; 35:1654-67

8. Esan O, Fawole O: Comparison of the profile of patients with acute and transient psychotic disorder and schizophrenia in a Nigerian teaching hospital. J Neuropsychiatry Clinical Neuroscience 2013; 25:327-334

9. Gratton $G$, Coles MG, Donchin E: A new method for offline removal of ocular artefact. Electroencephalogr Clin Neurophysiol 1983; 55:468-484

10. Hoptman MJ, Volavka J, Johnson G, Weiss E, Bilder RM, Lim KO: Frontal white matter microstructure, aggression, and impulsivity in men with schizophrenia: a preliminary study. Biol Psychiatry 2002; 52:9-14

11. Huster RJ, Enriquez-Geppert S, Lavallee CF, Falkenstein $M$, Herrmann CS: Electroencephalography of response inhibition tasks: functional networks and cognitive contributions. Int J Psychophysiol 2013; 87:217-33 
12. Jesulola E, Sharpley CF, Bitsika V, Agnew LL, Wilson P: Frontal alpha asymmetry as a pathway to behavioural withdrawal in depression: Research findings and issues. Behav Brain Res 2015; 292:56-67

13. Kaladjian A, Jeanningros R, Azorin JM, Anton JL, Mazzola-Pomietto P: Impulsivity and neural correlates of response inhibition in schizophrenia. Psychological Medicine 2011; 41:291-299

14. Kaladjian A, Jeanningros R, Azorin JM, Grimault S, Anton JL, Mazzola-Pomietto P: Blunted activation in right ventrolateral prefrontal cortex during motor response inhibition in schizophrenia. Schizophrenia Research 2007; 97:184-193

15. Kay SR, Fiszbein A, Opler LA: The positive and negative syndrome scale (PANSS) for schizophrenia. Schizophr Bull 1987; 13:261-276

16. Ko CH, Yen JY, Yen CF, Chen CS, Lin WC, Wang PW, Liu GC: Brain activation deficit in increased-load working memory tasks among adults with ADHD using fMRI. Eur Arch Psychiatry Clin Neurosci 2013; 263:561-573

17. Kopp B, Tabeling S, Moschner C, Wessel K: Fractionating the neural mechanisms of cognitive control. J Cogn Neurosci 2006; 18:949-965

18. Kumari V, Das M, Taylor PJ, Barkataki I, Andrew C, Sumich A, Williams SC, Ffytche DH: Neural and behavioural responses to threat in men with a history of serious violence and schizophrenia or antisocial personality disorder. Schizophrenia Research 2009; 110:47-58

19. Lin H, Gao H, You J, Liang J, Ma J, Yang N, Xu H, Jin H: Larger $N 2$ and smaller early contingent negative variation during the processing of uncertainty about future emotional events. Int J Psychophysiol 2014; 94:292-297

20. Lindenmayer JP, Brown E, Baker RW, Schuh LM, Shao L, Tohen M, Ahmed S, Stauffer VL: An excitement subscale of the Positive and Negative Syndrome Scale. Schizophrenia Research 2004; 68:331-337

21. Liu Y, Shen $X$, Zhu Y, Xu Y, Cai W, Shen M, Yu R, Wang $W$ : Mismatch negativity in paranoid, schizotypal, and antisocial personality disorders. Neurophysiol Clin 2007; 37:89-96

22. Luck SJ: An introduction to the event-related potential technique. MIT Press, 2005

23. Montemagni C, Badà A, Castagna F, Frieri T, Rocca G, Scalese M, Villari V, Rocca P: Predictors of compulsory admission in schizophrenia-spectrum patients: excitement, insight, emotion perception. Prog Neuropsychopharmacol Biol Psychiatry 2010; 35:137-145

24. Natsubori $T$, Inoue $H$, Abe $O$, Takano $Y$, Iwashiro $N$, Aoki Y Koike S, Yahata N, Katsura M, Gonoi W, Sasaki H, Takao H, Kasai K, Yamasue H: Reduced frontal glutamate + glutamine and $\mathrm{N}$-acetylaspartate levels in patients with chronic schizophrenia but not in those at clinical high risk for psychosis or with first-episode schizophrenia. Schizophr Bull 2014; 40:1128-1139

25. Neshige $R$, Lüders $H$ : Recording of event-related potentials (P300) from human cortex. J Clin Neurophysiol 1992; 9:294-8

26. Neuhaus AH, Goldberg TE, Hassoun $Y$, Bates JA, Nassauer KW, Sevy S, Opgen-Rhein C, Malhotra AK: Acute dopamine depletion with branched chain amino acids decreases auditory top-down event-related potentials in healthy subjects. Schizophr Res 2009; 111:167-73

27. Nigbur R, Ivanova G, Stürmer B: Theta power as a marker for cognitive interference. Clin Neurophysiol 2011; 122:2185-2194

28. Nishimura $Y$, Takizawa R, Muroi M, Marumo K, Kinou M, Kasai K: Prefrontal cortex activity during response inhibition associated with excitement symptoms in schizophrenia. Brain Res 2011; 1370;194-203

29. Oades RD, Wild-Wall N, Juran SA, Sachsse J, Oknina LB, Ropcke B: Auditory change detection in schizophrenia: sources of activity, related neuropsychological function and symptoms in patients with a first episode in adolescence, and patients 14 years after an adolescent illness-onset. BMC Psychiatry 2006; 6:7

30. O'Donnell BF, Vohs JL, Hetrick WP, Carroll CA, Shekhar A: Auditory event-related potential abnormalities in bipolar disorder and schizophrenia. Int J Psychophysiol 2004; 53:45-55

31. Patel SH, Azzam PN: Characterization of N200 and P300: selected studies of the Event-Related Potential. Int J Med Sci 2005; 2:147-154

32. Rangel-Gomez $M$, Hickey C, van Amelsvoort $T$, Bet $P$, Meeter M: The detection of novelty relies on dopaminergic signaling: evidence from apomorphine's impact on the novelty N2. PLoS One 2013; 8:e66469

33. Schiffer B, Müller BW, Scherbaum N, Forsting $M$, Wiltfang J, Leygraf N, Gizewski ER: Impulsivity-related brain volume deficits in schizophrenia-addiction comorbidity. Brain 2010; 133;3093-3103

34. Spitzer RL, Williams JBW, Gibbon $M$, First $M B$ : Structured Clinical Interview for DSM-III-R (SCID). American Psychiatric Press, Washington, DC, 1990

35. Sumich A, Castro A, Anilkumar A, Zachariah E, Kumari, $V$ : Neurophysiological correlates of excitement in schizophrenia. Progress in Neuro-Psychopharmacology \& Biological Psychiatry 2013; 46:132-138

36. Sumich A, Harris A, Flynn G, Whitford T, Tunstall N, Kumari V, Brammer M, Gordon E, Williams LM: Eventrelated potential correlates of depression, insight and negative symptoms in males with recent-onset psychosis. Clin Neurophysiol 2006; 117:1715-1727

37. Sumich A, Sarkar S, Hermens DF, Kelesidi K, Taylor E, and Rubia K: Electrophysiological correlates of CU traits show abnormal regressive maturation in adolescents with conduct problems. Personality and Individual Differences 2012; 53:862-867

38. Todd J, Michie PT, Schall U, Karayanidis F, Yabe H, Näätänen R: Deviant matters: duration, frequency, and intensity deviants reveal different patterns of mismatch negativity reduction in early and late schizophrenia. Biol Psychiatry 2008; 63:58-64

39. van der Gaag M, Hoffman T, Remijsen M, Hijman $R$, de Haan $L$, van Meijel B, van Harten PN, Valmaggia $L$, de Hert $M$, Cuijpers A, Wiersma D: The five-factor model of the Positive and Negative Syndrome Scale II: a ten-fold cross-validation of a revised model. Schizophrenia Research 2006; 85:280-287

40. van Veen V, Carter CS: The anterior cingulate as a conflict monitor: fMRI and ERP studies. Phys Behav 2002; 77:477-482 
41. Whelan R, Conrod PJ, Poline JB, Lourdusamy A, Banaschewski T, Barker GJ, Bellgrove MA, Büchel C, Byrne M, Cummins TD, Fauth-Bühler M, Flor H, Gallinat J, Heinz A, Ittermann B, Mann K, Martinot JL, Lalor EC, Lathrop M, Loth E, Nees F, Paus T, Rietschel M, Smolka $M N$, Spanagel R, Stephens DN, Struve M, Thyreau B, Vollstaedt-Klein S, Robbins TW, Schumann G, Garavan $H$. the IMAGEN Consortium: Adolescent impulsivity phenotypes characterized by distinct brain networks. Nat Neurosci 2012; 15:920-925
42. Williams LM, Simms E, Clark CR, Paul RH, Rowe D, Gordon E: The test-retest reliability of a standardized neurocognitive and neurophysiological test battery: "neuromarker". Int J Neurosci 2005; 115:1605-1630

43. Yang J, Ko YH, Paik JW, Lee MS, Han C, Joe SH, Jung IK, Jung HG, Kim SH: Symptom severity and attitudes toward medication: impacts on adherence in outpatients with schizophrenia. Schizophrenia Research 2012; 134:226-31

\section{Correspondence:}

Alexander Sumich, $M D$

Division of Psychology, Nottingham Trent University

Burton Street, Nottingham NG1 4BU, UK

E-mail: alexander.sumich@ntu.ac.uk 